\title{
Plasma human mammaglobin mRNA associated with poor outcome in patients with breast cancer
}

\author{
G.-W. Lee ${ }^{1,7 *}$, J.-Y. Kim ${ }^{2 *}$, E.-H. Koh ${ }^{3}$, D. Kang ${ }^{4}$, D.S. Choi ${ }^{5}$, \\ K.-Y. Maeng ${ }^{3}$ and J.-S. Lee ${ }^{6}$ \\ ${ }^{1}$ Department of Internal Medicine, School of Medicine, \\ Gyeongsang National University, Chilamdong, Jinju, South Korea \\ ${ }^{2}$ Department of Surgery, School of Medicine, \\ Gyeongsang National University, Chilamdong, Jinju, South Korea \\ ${ }^{3}$ Department of Laboratory Medicine, School of Medicine, \\ Gyeongsang National University, Chilamdong, Jinju, South Korea \\ ${ }^{4}$ Department of Physiology, School of Medicine, \\ Gyeongsang National University, Chilamdong, Jinju, South Korea \\ ${ }^{5}$ Department of Radiology, School of Medicine, \\ Gyeongsang National University, Chilamdong, Jinju, South Korea \\ ${ }^{6}$ Department of Pathology, School of Medicine, \\ Gyeongsang National University, Chilamdong, Jinju, South Korea \\ ${ }^{7}$ Department of Experimental Therapeutics, \\ University of Texas MD Anderson Cancer Center, Houston, TX, USA \\ *These authors contributed equally to this study. \\ Corresponding author: E.-H. Koh \\ E-mail: ehkohmd@gnu.ac.kr
}

Genet. Mol. Res. 11 (4): 4034-4042 (2012)

Received May 7, 2012

Accepted July 18, 2012

Published November 28, 2012

DOI http://dx.doi.org/10.4238/2012.November.28.2

\begin{abstract}
Different treatment outcomes and prognoses in patients with breast cancer can be observed with similar clinical predictors; this is because the biology of breast cancer is complex and heterogenous, involving multiple unknown contributing factors. We looked for plasma human mammaglobin (hMAM) mRNA by RT-PCR in 82 Korean patients with breast cancer to determine if there is an association
\end{abstract}


between the presence of plasma hMAM mRNA in these patients and known prognostic factors. The prognostic usefulness of detection of plasma hMAM mRNA expression in these patients was also evaluated by determining overall survival and event-free survival. A significant difference was observed in the rate of positivity of plasma hMAM mRNA between the early stages of cancer (stages I-II, 23.4\%) and advanced stages (stages III-IV, 82.9\%). The expression rates of estrogen receptor, progesterone receptor, and HER-2/neu in the breast tissue of these patients, by immunohistochemistry, were $69.5,75.6$, and $20.7 \%$, respectively. In the univariate analysis, plasma hMAM expression was significantly correlated with high histological and nuclear grades, nodal metastasis, and negative estrogen receptor and progesterone receptor status. Patients negative for plasma hMAM mRNA had significantly higher rates of event-free survival compared to the patients positive for plasma hMAM mRNA. However, no significant association with overall survival was observed for expression of plasma hMAM mRNA $(\mathrm{P}=0.16)$. Qualitative detection of plasma hMAM mRNA appears to be associated with unfavorable prognostic factors and lower rates of event-free survival in patients with breast cancer.

Key words: Human mammaglobin; Breast cancer; Biomarker; Prognostic factor

\section{INTRODUCTION}

Breast cancer is the most common malignancy in women in developed countries. It has been the most common cancer among Korean women since 2002, and its incidence is rapidly increasing in Korea (Bae et al., 2002; Jung et al., 2011). Currently available clinical predictors of breast cancer include the clinical stage of the disease, involvement of axillary lymph nodes (LNs), number of axillary LN metastases, histologic grade, nuclear grade, hormone receptor status, presence of lymphovascular emboli, and expression of HER-2/neu (cerbB2). However, different treatment outcomes and prognoses can be observed with similar clinical predictors, even in patients with the same stage of breast cancer, because the biology of breast cancer is complex and heterogeneous, with multiple unknown factors contributing to its carcinogenesis, relapse, progression, and metastasis (Keen and Davidson, 2003). Thus, many diagnostic and prognostic biomarkers in breast cancer have been suggested to precisely determine the prognosis and treatment outcomes of these patients for the last two decades.

Human mammaglobin (hMAM) mRNA is considered to be a promising candidate for a sensitive molecular marker for breast cancer (Watson and Fleming, 1996). hMAM is expressed mainly by breast epithelial cells, and this feature has been used to detect circulating breast cancer cells and occult metastases in sentinel axillary LNs of patients with the disease (Roncella et al., 2005). However, the biological role of hMAM is not fully understood, and whether hMAM plays an important role as a biomarker in breast cancer regarding early detection, treatment outcomes, and prognosis is still under debate.

The aim of this study was to investigate the expression of hMAM mRNA in the plas- 
ma of patients with breast cancer according to clinical stage and to analyze the association between the presence of hMAM mRNA in the plasma of these patients and known prognostic factors such as histologic grade, nuclear grade, tumor size, stage, LN status, estrogen receptor (ER) and progesterone receptor (PR) status, and c-erbB2 expression. Overall survival (OS) and event-free survival (EFS) were also estimated to evaluate the prognostic usefulness of plasma hMAM expression in patients with breast cancer.

\section{PATIENTS AND METHODS}

\section{Patients}

Ninety-eight subjects admitted to the Cancer Center at Gyeongsang National University Hospital from October 2007 through December 2010 were included in this study. The patients' ages ranged from 26 to 82 years, with a median of 50 years. The diagnosis of breast cancer and clinical stages and pathological features of primary tumors were defined according to the criteria of the American Joint Commission on Cancer. Among these patients, 74 had tumors with invasive ductal carcinoma, 3 had invasive mucinous carcinoma, and 5 had other types, such as invasive lobular carcinoma or invasive medullary carcinoma. Sixteen patients with benign breast tumors and no previous history of neoplastic disease served as benign controls. The clinicopathologic characteristics of the patients with breast cancer are summarized in Table 1. This study was conducted according to an institutional review board-approved protocol.

\section{Total RNA extraction in the plasma and cDNA synthesis}

Peripheral blood (PB) samples $(10 \mathrm{~mL})$ were taken from the patients prior to surgery or treatments including best supportive care and from benign controls after informed consent and were placed in EDTA tubes. After centrifugation of the blood samples at $3500 \mathrm{rpm}$ for $15 \mathrm{~min}$ at $4^{\circ} \mathrm{C}$, the plasma was collected and kept at $-80^{\circ} \mathrm{C}$ until RNA extraction. RNA was extracted from $5 \mathrm{~mL}$ plasma for hMAM analysis using a QIAamp Circulating Nucleic Acid kit (Qiagen GmbH, Hilden, Germany) according to manufacturer instructions. Ten microliters of RNA from the plasma was transcribed to cDNA by reverse transcriptase (RT) in a total $20-\mu \mathrm{L}$ RT reaction solution containing $2 \mu \mathrm{L}$ 10X RT buffer, $500 \mu \mathrm{M}$ dNTP, $200 \mu \mathrm{M}$ random hexamer primer, $10 \mathrm{U}$ RNase inhibitor, and $10 \mathrm{U}$ Sensiscript Reverse Transcriptase (Qiagen $\mathrm{GmbH}$ ) at $37^{\circ} \mathrm{C}$ for $60 \mathrm{~min}$.

\section{RT-PCR for plasma hMAM mRNA and MCF-7 cell line}

RT-PCR was carried out with $4 \mu \mathrm{L}$ cDNA, specific sense and antisense primers, and master mix (Promega, Madison, WI, USA) in a total volume of $25 \mu \mathrm{L}$. The primers for hMAM (NM_002411) used were 5'-GCTGCCCCTTATTGGAGAAT-3' (sense) and 5'-TGGCATTTGTAGTGGCATTG-3' (antisense). The conditions of RT-PCR were as follows: denaturing at $95^{\circ} \mathrm{C}$ for $30 \mathrm{~s}$, annealing at $60^{\circ} \mathrm{C}$ for $30 \mathrm{~s}$, and elongation at $72^{\circ} \mathrm{C}$ for $30 \mathrm{~s}(40$ cycles), and final cycle at $72^{\circ} \mathrm{C}$ for $5 \mathrm{~min}$. After amplification, $10 \mu \mathrm{L}$ of each product was run for $30 \mathrm{~min}$ at $100 \mathrm{~V}$ and detected by ethidium bromide staining on a $2.5 \%$ agarose gel. The bands were detected in an ultraviolet transilluminator and photographed with a Gel Doc XR (Bio-Rad, Segrate, Italy). In the preliminary study, PCR products were sequenced and confirmed using 
the BigDye Terminator Cycle Sequencing Ready Reaction kit (Applied Biosystems, Foster City, CA, USA) and the BLAST program (http://ncbi.nlm.nih.gov) provided by the National Center for Biotechnology Information (NCBI). As an internal control, the glyceraldehyde 3-phosphate dehydrogenase (GAPDH) gene amplification was carried out for each cDNA sample under conditions identical to those for hMAM amplification. The primers for GAPDH were 5'-GAAGGTGAAGGTCGGAGTC-3' (sense) and 5'-GAAGATGG TGATGGGATTC-3' (antisense). The breast cancer cell line MCF-7 was obtained from the Korean Cell Line Bank (Seoul, Korea) and used as an hMAM mRNA-positive control.

To establish the limit of sensitivity tests of the RT-PCR assays, serial dilutions of cDNA of $10^{5}$ cells of the breast cancer cell line MCF-7 were subjected to RT-PCR. The highest detection sensitivity observed was $10 \mathrm{MCF}-7$ cells in the RT-PCR.

\section{Immunohistochemistry}

Immunohistochemistry was used to measure the protein expression levels of ER, PR, and c-erbB2. The following panel of monoclonal antibodies was applied: anti-ER Mab (clone 1D5, dilution 1:20; Dako, Carpinteria, CA, USA), anti-PR Mab (clone 1A6, dilution 1:20; Dako), and anti-c-erbB2 Mab (clone CB11, dilution 1:20; Neomarkers, Fremont, CA, USA). ER and PR staining cells were considered to be positive only when distinct nuclear staining was identified and $25 \%$ of tumor cells showed positive staining. For c-erbB2 staining, only the membrane staining was considered positive, and the score for c-erbB2 staining was graded. A score of $0,1+$, and $2+$ was considered to be negative, whereas $3+$ was considered to be positive.

\section{Statistical analysis}

The Pearson two-sided $\chi^{2}$ test and the Fisher exact test were used to assess the correlation between plasma hMAM mRNA and histological grade, nuclear grade, tumor size, stage, LN status, ER and PR status, and c-erbB2 expression.

Survival probability analyses were performed using the Kaplan-Meier method. OS was calculated from the date that PB samples were taken for RT-PCR to the date of death or most recent follow-up. In this study, EFS was defined as the date that PB samples were taken for RT-PCR until disease progression or recurrence, or death of any cause. The significance between group differences was assessed by the log-rank test. Multivariate analyses were performed using Cox regression models for OS. Factors with $\mathrm{P}<0.1$ in univariate analyses were examined with multivariate regression models. A probability of $<0.05$ was considered to be statistically significant. All statistical analyses were performed using the Statistical Package for Social Sciences version 18.0 (SPSS Inc., Chicago, IL, USA).

\section{RESULTS}

\section{Detection of plasma hMAM mRNA in patients with breast cancer}

Plasma hMAM mRNA was detected in 40 of $82(48.8 \%)$ patients with breast cancer (Figure 1). hMAM mRNA was found in 4 of $32(12.5 \%)$ stage I patients, 7 of $15(47.0 \%)$ stage II patients, 4 of $7(57.1 \%)$ stage III patients, and 25 of 28 (82.9\%) stage IV patients. A signifi- 
cant difference in positive rates was observed between stage I and stage II patients $(23.4 \%)$ and between stage III and stage IV patients $(82.9 \%)(\mathrm{P}<0.05)$ (Table 1$)$. No plasma hMAM mRNA was detected in the 16 benign controls.
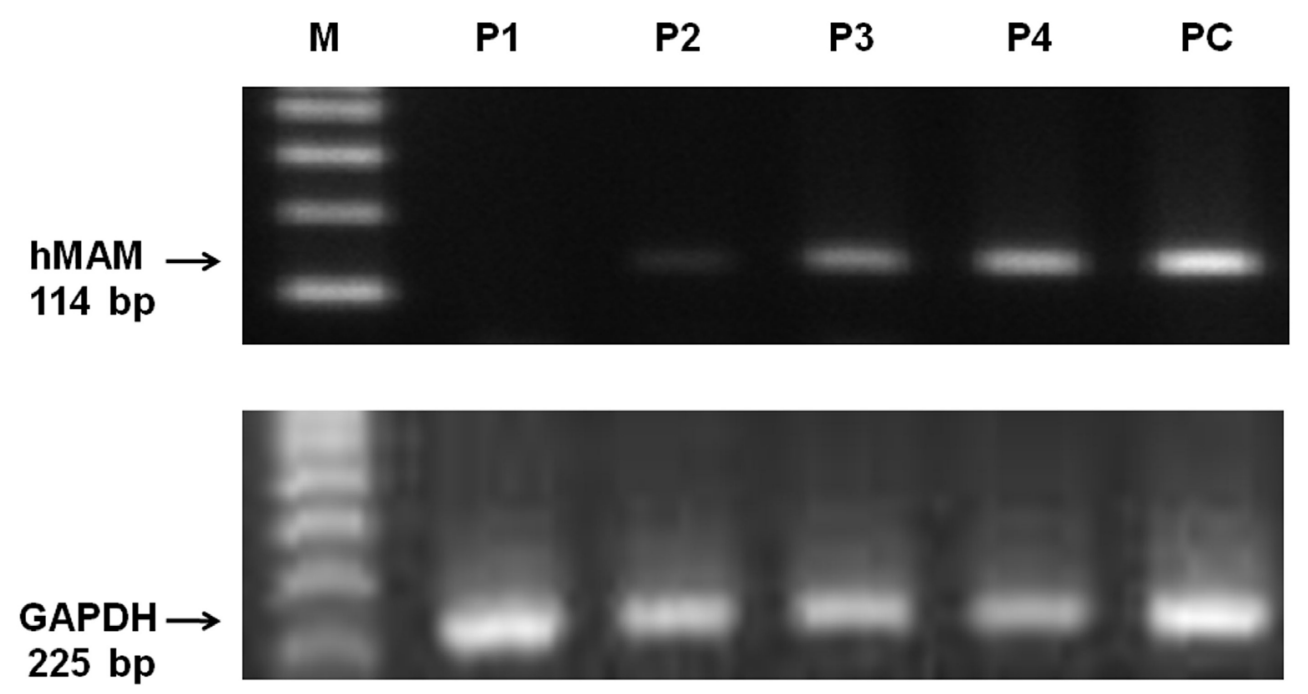

Figure 1. Human mammaglobin (hMAM) mRNA and GAPDH mRNA in the plasma detected by RT-PCR in patients with breast cancer. Top, hMAM RT-PCR product (114 bp); bottom, GAPDH (225 bp) internal control. Lane $M=$ molecular weight marker; lane $P 1=$ benign breast disease; lanes $P 2$ to $P 4=$ breast cancer; lane $P C=$ MCF-7 breast cell line used as a positive control.

Table 1. Univariate analysis of plasma human mammaglobin (hMAM) mRNA in patients with breast cancer and clinical and biological variables.

\begin{tabular}{|c|c|c|c|}
\hline Variable & Number & $\begin{array}{l}\text { hMAM mRNA } \\
\text { [Positive (\%)] }\end{array}$ & $P$ \\
\hline \multicolumn{4}{|c|}{ Histologic grade } \\
\hline 1 & 23 & $3(13.0)$ & \\
\hline $2-3$ & 59 & $37(62.7)$ & $<0.001$ \\
\hline \multicolumn{4}{|c|}{ Nuclear grade } \\
\hline 1 & 25 & $4(16.0)$ & \\
\hline $2-3$ & 57 & $36(63.2)$ & $<0.001$ \\
\hline \multicolumn{4}{|c|}{ Nodal metastasis } \\
\hline No & 42 & $10(23.8)$ & \\
\hline Yes & 40 & $30(75.0)$ & $<0.001$ \\
\hline \multicolumn{4}{|l|}{ Stage } \\
\hline $\mathrm{I}+\mathrm{II}$ & 47 & $11(23.4)$ & \\
\hline $\mathrm{III}+\mathrm{IV}$ & 35 & $29(82.9)$ & $<0.001$ \\
\hline \multicolumn{4}{|c|}{ Estrogen receptor } \\
\hline Negative & 25 & $17(68.0)$ & 0.030 \\
\hline Positive & 57 & $23(40.4)$ & \\
\hline \multicolumn{4}{|c|}{ Progesterone receptor } \\
\hline Negative & 20 & $14(70.0)$ & \\
\hline & 62 & $26(41.9)$ & 0.040 \\
\hline \multicolumn{4}{|l|}{ c-erbB2 } \\
\hline Negative & 65 & $31(47.7)$ & \\
\hline Positive & 17 & $9(52.9)$ & 0.788 \\
\hline
\end{tabular}




\section{Clinicopathologic features of patients with breast cancer in association with plasma hMAM mRNA}

hMAM mRNA expression was significantly correlated $(\mathrm{P}<0.001)$ with high histologic grade and nuclear grade, nodal metastasis, and higher stage. The expression rates of ER, PR, and c-erbB2 in breast tissue were $69.5,75.6$, and $20.7 \%$, respectively, among the patients with breast cancer. Plasma hMAM mRNA was significantly correlated with negative ER $(\mathrm{P}=0.030)$ and PR status $(\mathrm{P}=0.040)$, but no significant association was observed between hMAM mRNA in plasma and c-erbB2 in breast cancer tissue $(\mathrm{P}=0.788)$. Detection of plasma hMAM mRNA is associated with unfavorable prognostic factors for breast cancer, including negative ER and PR status, advanced stage, LN involvement, and high histologic and nuclear grade (Table 1).

\section{Survival and clinicopathologic features of patients with breast cancer}

With a median follow-up of 20.9 months (range $=14.5-62.1$ months), median OS was 48.1 months (range $=36.4-59.5$ months) in this study. On univariate analysis, better OS was significantly associated with low histologic grade (grade 1 vs 2-3) $(\mathrm{P}=0.022)$, low nuclear grade (grade 1 vs 2-3) $(\mathrm{P}=0.030)$, negative-axillary lymph node involvement $(\mathrm{P}=0.004)$, and low stage (stages I-II vs III-IV) $(\mathrm{P}<0.001)$ (Table 2). However, no significant difference in OS was observed according to the expression of hMAM mRNA $(\mathrm{P}=0.160)$ (Figure $2 \mathrm{~A})$. In EFS analysis, the patients with negative hMAM mRNA showed statistically better survival compared to the patients with positive hMAM mRNA $(\mathrm{P}=0.012)$ (Figure $2 \mathrm{~B})$.

Table 2. Univariate analysis for overall survival (OS) and event-free survival (EFS) of patients with breast cancer.

\begin{tabular}{|c|c|c|c|c|}
\hline Variable & $\begin{array}{c}\text { Median OS } \\
\text { (95\%CI, months) }\end{array}$ & $\mathrm{P}$ in $\mathrm{OS}$ & $\begin{array}{c}\text { Median EFS } \\
\text { (95\%CI, months) }\end{array}$ & $P$ in EFS \\
\hline Histologic grade & & 0.022 & & 0.006 \\
\hline 1 & NR & & $31.1(28.9-59.1)$ & \\
\hline $2-3$ & $39.6(21.2-58.6)$ & & $25.5(18.6-43.5)$ & \\
\hline Nuclear grade & & 0.030 & & 0.001 \\
\hline 1 & NR & & NR & \\
\hline $2-3$ & $42.2(34.3-51.2)$ & & $24.8(15.8-41.3)$ & \\
\hline Nodal metastasis & & 0.004 & & $<0.001$ \\
\hline Negative & NR & & NR & \\
\hline Positive & $39.6(8.5-70.7)$ & & $20.1(17.4-22.9)$ & \\
\hline Estrogen receptor & & 0.077 & & 0.108 \\
\hline Negative & $35.2(30.4-43.1)$ & & $25.5(9.8-38.2)$ & \\
\hline Positive & $44.5(34.5-49.9)$ & & $31.4(18.7-40.2)$ & \\
\hline Progesterone receptor & & 0.806 & & 0.108 \\
\hline Negative & $41.8(33.4-48.1)$ & & $28.5(7.3-43.7)$ & \\
\hline Positive & $42.2(37.2-48.5)$ & & $30.1(27.5-36.3)$ & \\
\hline c-erbB2 & & 0.220 & & 0.353 \\
\hline Negative & $43.7(33.8-52.9)$ & & $31.1(12.1-49.8)$ & \\
\hline Positive & $42.1(32.3-51.4)$ & & $26.3(22.8-30.7)$ & \\
\hline hMAM & & 0.155 & & 0.012 \\
\hline Negative & NR & & NR & \\
\hline Positive & $33.5(17.4-66.3)$ & & $25.5(18.9-32.1)$ & \\
\hline Tumor size & & 0.113 & & $<0.001$ \\
\hline$<5 \mathrm{~cm}$ & $52.2(42.1-63.4)$ & & $31.1(22.9-40.2)$ & \\
\hline$\geq 5 \mathrm{~cm}$ & $29.3(21.2-56.9)$ & & $18.1(12.1-23.7)$ & \\
\hline Stage & & $<0.001$ & & $<0.001$ \\
\hline I-II & NR & & NR & \\
\hline III-IV & $39.6(21.1-58.3)$ & & $18.2(11.6-24.1)$ & \\
\hline
\end{tabular}



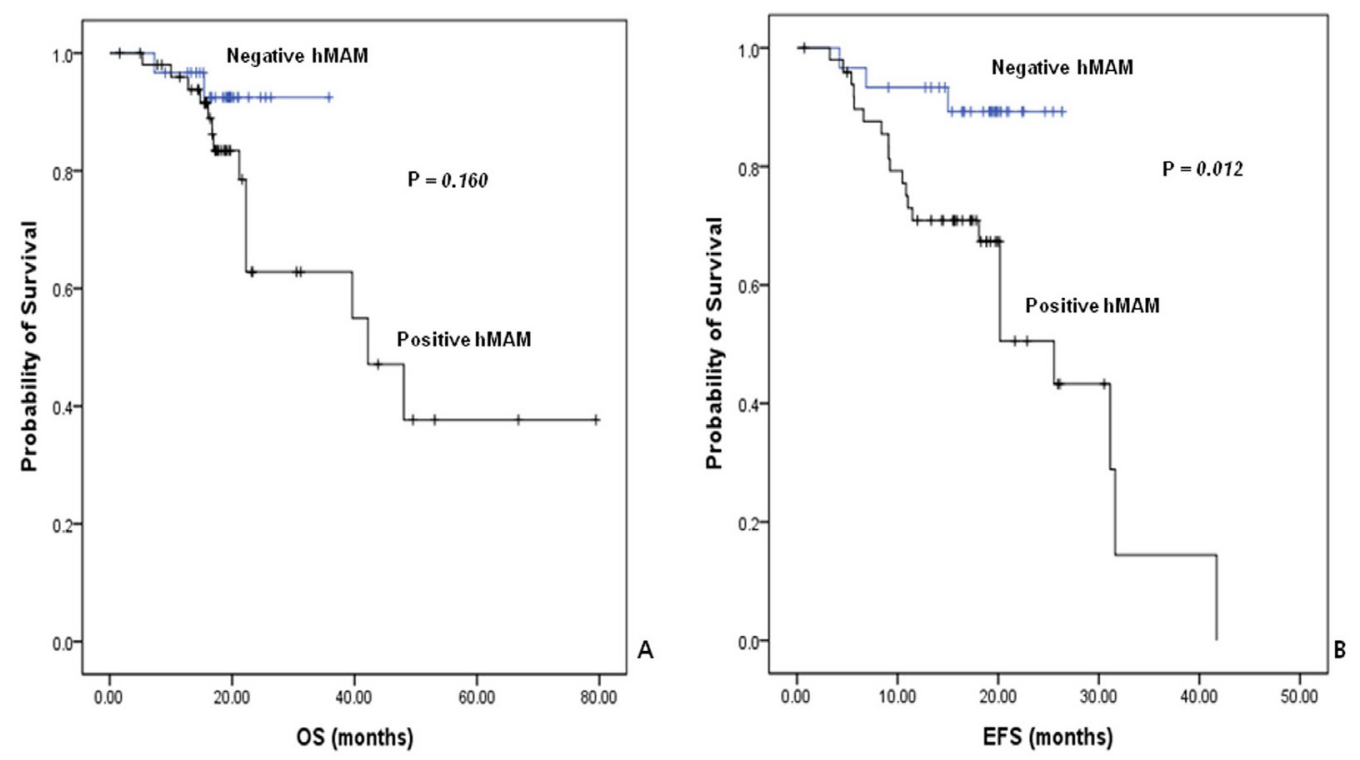

Figure 2. Overall survival (OS) and event-free survival (EFS) of patients with breast cancer according to the expression of plasma human mammaglobin (hMAM) mRNA.

Moreover, better EFS was observed in patients with low histologic grade $(\mathrm{P}=0.006)$, low nuclear grade $(\mathrm{P}=0.001), \mathrm{T} 1-2$ stage (less than $5 \mathrm{~cm})(\mathrm{P}<0.001)$, negative-axillary lymph node involvement $(\mathrm{P}<0.001)$, and low stage $(\mathrm{P}<0.001)$ (Table 2$)$. Multivariate analysis revealed that stage is a solely independent predictor of EFS (hazard ratio $=2.75 ; 95 \%$ confidence interval $=2.08-6.92 ; \mathrm{P}=0.012)$ as well as $\mathrm{OS}$ (hazard ratio $=3.13 ; 95 \%$ confidence interval $=$ 2.26-5.01; $\mathrm{P}=0.010)$.

\section{DISCUSSION}

Despite recent advances in the early diagnosis and treatment of breast cancer, metastatic disease occurs in approximately $50 \%$ of cases with apparently localized breast cancer at initial presentation; even $30 \%$ of patients with axillary LN-negative disease may develop distant metastases (Braun et al., 2001). Many previous studies have attempted to search for novel and more reliable molecular biomarkers for early detection of occult metastases (Stacker et al., 2002; Tafreshi et al., 2011); however, traditional clinical and pathologic predictors based on the St. Gallen and similar international consensus recommendations are still used as determinants of treatment outcomes and prognosis in breast cancer. This study found that plasma hMAM mRNA expression was significantly associated with unfavorable prognostic factors for breast cancer, which parallels the St. Gallen high-risk categories, including negative ER and PR status, high histologic grade, high nuclear grade, advanced stage, and axillary LN involvement, providing evidence that molecular detection of hMAM mRNA may have clinical correlation and significance. However, overexpression of c-erbB2, which is currently accepted as one of the most important prognostic factors for breast cancer, was not correlated with hMAM. 
Italian investigators showed that poorer disease-free survival was found in patients with breast cancer who had been operated, with hMAM mRNA detected by nested RT-PCR in either bone marrow or PB, as compared to hMAM mRNA-negative patients, and only nodalpositive status was correlated with a positive hMAM mRNA on univariate analysis (Fortunato et al., 2009). Another study revealed that hMAM gene expression on leukapheresis products showed a significant correlation with an increased risk of relapse in high-risk patients with breast cancer who received high-dose chemotherapy followed by peripheral blood progenitor cell rescue and that this can be used as an indicator of poor prognosis (Ferrucci et al., 2004).

Similarly, an Austrian study reported that the incidence of detectable hMAM transcripts in PB of patients with breast cancer was correlated with the clinical stage of disease ( $28 \%$ in patients at diagnosis of breast cancer, $49 \%$ in patients with metastatic disease, and $6 \%$ in patients with no evidence of disease) and elevated plasma carcinoembryonic antigen levels (Zach et al., 1999). The positive rates of hMAM mRNA were similar to those in our results. A significant difference in positive rates was observed between patients with early stage cancer (23.4\%) and those with advanced stage cancer $(82.9 \%)$. Positive rates of hMAM mRNA in PB from invasive breast cancer varied from 8 to $61 \%$ among previous studies (Grunewald et al., 2000; Zehentner et al., 2004; Benoy et al., 2006). Our study also showed that hMAM mRNA was significantly associated with unfavorable prognostic factor and inferior EFS on univariate analysis. However, hMAM mRNA was not correlated with OS. Additionally, this investigation failed to demonstrate an important role of hMAM mRNA as the independent prognostic factor in patients with breast cancer on multivariate analysis.

The inconsistent outcomes between hMAM mRNA expression and important prognostic factors of breast cancer, compared to previous studies, could be explained by the differences in the number of patients studied, age, stage (early operable disease $v s$ metastatic disease), performance status, applied evolving treatments, molecular characteristics, or other technical variables, including the amount of blood collected, storage, and RT-PCR method (primers, reagents, and PCR conditions). Additionally, no standardized method to detect circulating nucleic acid has been established. Quantitative real-time PCR may result in a more effective evaluation of the clinical significance of plasma mRNA in risk prediction and treatment monitoring; however, a real-time PCR instrument was not available at the time of our analyses. Constant volume and quality of RNA solutions prepared from $5 \mathrm{~mL}$ plasma using a QIAamp Circulating Nucleic Acid kit (Qiagen $\mathrm{GmbH}$ ) were used in this study to overcome the RT-PCR problem.

Among the various factors associated with high-risk patients, the most important factor discriminating clinicopathologic profiles, treatment outcome, and prognosis is the hormone receptor status. ER-/PR-positive breast cancers are biologically quite different from ER-/PR-negative cancers across races (Gruvberger et al., 2001).

Our results also demonstrated a significant association between plasma hMAM mRNA and ER-/PR-negative status, reflecting an aggressive phenotype. Some previous studies, however, reported a correlation between high levels of hMAM and a low-risk group that had positive expression of ER and PR using fresh-frozen breast cancer specimens by means of RTPCR (Núñez-Villar et al., 2003; Span et al., 2004). The discrepancy between previous studies and our results may be explained by differences in experimental specimens (plasma vs frozen breast cancer tissues), or ethnic differences [Caucasian vs Asian (Korean)] (Span et al., 2004; Gormally et al., 2007).

In conclusion, plasma hMAM mRNA was associated with unfavorable prognostic 
factors and inferior EFS of breast cancer, although further studies are needed to evaluate the prognostic usefulness of hMAM expression itself in patients with breast cancer.

\section{ACKNOWLEDGMENTS}

Research supported by the Clinical Research Promotion Program (GNUHCRF-2010004), Gyeongsang National University Hospital.

\section{REFERENCES}

Bae JM, Won YJ, Jung KW and Park JG (2002). Annual report of the Korea central cancer registry program 2000: Based on registered data from 131 hospitals. Cancer Res. Treat. 34: 77-83.

Benoy IH, Elst H, Philips M, Wuyts H, et al. (2006). Real-time RT-PCR detection of disseminated tumour cells in bone marrow has superior prognostic significance in comparison with circulating tumour cells in patients with breast cancer. Br. J. Cancer 94: 672-680.

Braun S, Cevatli BS, Assemi C, Janni W, et al. (2001). Comparative analysis of micrometastasis to the bone marrow and lymph nodes of node-negative breast cancer patients receiving no adjuvant therapy. J. Clin. Oncol. 19: 1468-1475.

Ferrucci PF, Rabascio C, Mazzetta C, Cocorocchio E, et al. (2004). Mammaglobin expression in leukapheresis products is a predictive marker of poor prognosis in women with high-risk breast cancer. Clin. Cancer Res. 10: 6039-6046.

Fortunato L, Mascaro A, Baldi A, Farina M, et al. (2009). Positive bone marrow biopsy is associated with a decreased disease-free survival in patients with operable breast cancer. Ann. Surg. Oncol. 16: 3010-3019.

Gormally E, Caboux E, Vineis P and Hainaut P (2007). Circulating free DNA in plasma or serum as biomarker of carcinogenesis: practical aspects and biological significance. Mutat. Res. 635: 105-117.

Grunewald K, Haun M, Urbanek M, Fiegl M, et al. (2000). Mammaglobin gene expression: a superior marker of breast cancer cells in peripheral blood in comparison to epidermal-growth-factor receptor and cytokeratin-19. Lab. Invest. 80: 1071-1077.

Gruvberger S, Ringner M, Chen Y, Panavally S, et al. (2001). Estrogen receptor status in breast cancer is associated with remarkably distinct gene expression patterns. Cancer Res. 61: 5979-5984.

Jung KW, Park S, Kong HJ, Won YJ, et al. (2011). Cancer statistics in Korea: incidence, mortality, survival, and prevalence in 2008. Cancer Res. Treat. 43: 1-11.

Keen JC and Davidson NE (2003). The biology of breast carcinoma. Cancer 97: 825-833.

Núñez-Villar MJ, Martinez-Arribas F, Pollan M, Lucas AR, et al. (2003). Elevated mammaglobin (h-MAM) expression in breast cancer is associated with clinical and biological features defining a less aggressive tumour phenotype. Breast Cancer Res. 5: R65-R70.

Roncella S, Ferro P, Bacigalupo B, Pronzato P, et al. (2005). Human mammaglobin mRNA is a reliable molecular marker for detecting occult breast cancer cells in peripheral blood. J. Exp. Clin. Cancer Res. 24: 265-271.

Span PN, Waanders E, Manders P, Heuvel JJ, et al. (2004). Mammaglobin is associated with low-grade, steroid receptorpositive breast tumors from postmenopausal patients, and has independent prognostic value for relapse-free survival time. J. Clin. Oncol. 22: 691-698.

Stacker SA, Achen MG, Jussila L, Baldwin ME, et al. (2002). Lymphangiogenesis and cancer metastasis. Nat. Rev. Cancer 2: 573-583.

Tafreshi NK, Enkemann SA, Bui MM, Lloyd MC, et al. (2011). A mammaglobin-A targeting agent for noninvasive detection of breast cancer metastasis in lymph nodes. Cancer Res. 71: 1050-1059.

Watson MA and Fleming TP (1996). Mammaglobin, a mammary-specific member of the uteroglobin gene family, is overexpressed in human breast cancer. Cancer Res. 56: 860-865.

Zach O, Kasparu H, Krieger O, Hehenwarter W, et al. (1999). Detection of circulating mammary carcinoma cells in the peripheral blood of breast cancer patients via a nested reverse transcriptase polymerase chain reaction assay for mammaglobin mRNA. J. Clin. Oncol. 17: 2015-2019.

Zehentner BK, Persing DH, Deme A, Toure P, et al. (2004). Mammaglobin as a novel breast cancer biomarker: multigene reverse transcription-PCR assay and sandwich ELISA. Clin. Chem. 50: 2069-2076. 